\title{
The diagnostic accuracy of endovaginal and transperineal ultrasound for detecting anal sphincter defects: The PREDICT study
}

\author{
A.-M. Roos ${ }^{\mathrm{a}, *}$, Z. Abdool ${ }^{\mathrm{b}}$, A.H. Sultan ${ }^{\mathrm{a}}, \mathrm{R}$. Thakar $^{\mathrm{a}}$ \\ a Department of Obstetrics and Gynaecology, Mayday University Hospital, Croydon, UK \\ ${ }^{\mathrm{b}}$ Department of Obstetrics and Gynaecology, University of Pretoria, Pretoria, South Africa
}

\section{ARTICLE INFORMATION}

\section{Article history:}

Received 17 August 2010

Received in revised form

21 November 2010

Accepted 24 November 2010
AIM: To determine the accuracy and predictive value of transperineal (TPU) and endovaginal ultrasound (EVU) in the detection of anal sphincter defects in women with obstetric anal sphincter injuries and/or postpartum symptoms of faecal incontinence.

MATERIALS AND METHODS: One hundred and sixty-five women were recruited, four women were excluded as they were seen years after their last delivery. TPU and EVU, followed by endonanal ultrasound (EAU), were performed using the B\&K Viking 2400 scanner. Sensitivity and specificity, as well as predictive values with 95\% confidence intervals, for detecting anal sphincter defects were calculated for EVU and TPU, using EAU as the reference standard.

RESULTS: On EAU a defect was found in 42 (26\%) women: 39 (93\%) had an external (EAS) and 23 (55\%) an internal anal sphincter (IAS) defect. Analysable images of one level of the EAS combined with an analysable IAS were available in 140 (87\%) women for EVU and in 131 (81\%) for TPU. The sensitivity and specificity for the detection of any defect was $48 \%(30-67 \%)$ and 85\% (77-91\%) for EVU and 64\% (44-81\%) and 85\% (77-91\%) for TPU, respectively.

CONCLUSION: Although EAU using a rotating endoprobe is the validated reference standard in the identification of anal sphincter defects, it is not universally available. However while TPU and/or EVU with conventional ultrasound probes can be useful in identifying normality, for clinical purposes they are not sensitive enough to identify an underlying sphincter defect.

(C) 2011 The Royal College of Radiologists. Published by Elsevier Ltd. All rights reserved.

\section{Introduction}

Endoanal ultrasound (EAU) was the first sonographic method used to evaluate the anal sphincter complex and was responsible for improving our understanding of the basic concepts underlying the continence mechanism. Following its discovery in the late $1980 \mathrm{~s}^{1}$ it is currently

\footnotetext{
* Guarantor and correspondent: A.-M. Roos, Department of Obstetrics and Gynaecology, Mayday University Hospital, 530 London Road, Croydon, Surrey CR7 7YE, UK. Tel.: +44 (0)208 401 3154; fax: +44 (0)208 4103681.

E-mail address: annemarie.roos@gmail.com (A.-M. Roos).
}

regarded as the reference standard for identifying sphincter defects. ${ }^{2,3}$ Further introduction of three-dimensional (3D) volume imaging has enabled accurate diagnostic evaluation of the full extent of the anal sphincter defect. ${ }^{4}$ However, some patients find EAU embarrassing, the equipment is not universally available, and it requires a trained operator. Furthermore, the internal probe may cause disruption of the normal anatomy of the anal sphincter. Therefore, the use of other imaging techniques, such as endovaginal ultrasound $(\mathrm{EVU})^{5-15}$ and transperineal ultrasound (TPU), ${ }^{16-19}$ have been described.

In 1994, Sultan et al. ${ }^{5}$ first described the vaginal approach to visualize the anal sphincter, using the $360^{\circ}$ rotating 
endoprobe also used for EAU. They were able to clearly image the anal canal, submucosa, internal (IAS), and external (EAS) anal sphincters. They found that, compared with EAU, the IAS was thicker, because the anal sphincter was not stretched by an internal probe. However, difficulty in interpreting EVU images has been reported in up to $24 \%$ of women. ${ }^{8,9}$ Further studies have been able to describe both normal anatomy as well as anal sphincter disruptions with EVU using a vaginally inserted side-fire transrectal probe, ${ }^{10,11}$ a linear "small parts" transducer, ${ }^{14}$ and a standard, vaginal probe, ${ }^{6,12,13,15}$ the latter two of which were placed at the vaginal introitus. Frudinger et al. ${ }^{7}$ used a $10 \mathrm{MHz}$ rectal endoprobe and a $10 \mathrm{MHz}$ modified vaginal probe and found that the sensitivity and specificity of EVU for the detection of IAS defects was 44 and $96 \%$ and for EAS defects was 48 and 88\%, respectively, taking EAU as the reference standard.

Following the use of EVU in imaging of the anal sphincter, Peschers et al. ${ }^{16}$ first described TPU for imaging the anal canal using a convex scanner. Using this technique in both symptomatic and asymptomatic women, they were able to detect both IAS and EAS defects, with 100\% agreement between two examiners for IAS defects and agreement in all but one defect of the EAS. When TPU was compared with EAU in a group of females complaining only of urinary incontinence, the sensitivity of detecting sphincter lesions using TPU was 50\% and the specificity $84 \%{ }^{17}$ However, using TPU, Roche et al. ${ }^{18}$ recognized all isolated EAS and combined IAS and EAS defects and all but one isolated IAS defect.

Endosonographic evidence of trauma to the EAS and IAS is predictive of faecal incontinence following obstetric anal sphincter injuries (OASIs). ${ }^{20-23}$ However, information regarding the integrity of the anal sphincter is not only important in symptomatic patients, but also in asymptomatic women for effective counselling regarding mode of delivery during subsequent pregnancies. ${ }^{24}$

$\mathrm{TPU}^{25}$ and $\mathrm{EVU}^{12,26}$ have both been used in the postpartum evaluation of the anal sphincter following vaginal delivery with or without the presence of OASIs. Furthermore EVU has been described in pregnant women, ${ }^{26}$ but the accuracy of both methods in comparison with EAU in these groups of patients remains to be established.

The aim of this study was to determine the sensitivity, specificity, and predictive value of TPU and EVU in the detection of anal sphincter defects, in women following OASIs and/or presenting postpartum with symptoms of faecal incontinence.

\section{Materials and methods}

All patients were recruited from the one-stop perineal clinic at Mayday University hospital. The perineal clinic is a consultant-led clinic for women with perineal complaints and pelvic floor symptoms that occur during pregnancy or postpartum. Women who sustain OASIs and have primary repair are seen in the perineal clinic for routine follow up between 10 to 12 weeks post-partum. In addition, pregnant women with previous OASIs are evaluated and counselled regarding mode of delivery. ${ }^{27}$ All women who were referred to the perineal clinic after sustaining OASIs and/or with post-partum symptoms of anal incontinence, who were able to understand and read English, were eligible for participation in this study. This study was granted ethical approval by the London-Surrey Borders Research Ethics Committee (08/H0806/76).

Clinical history was obtained and a modified St Marks Incontinence Score ${ }^{28}$ was completed by the clinician for all patients. The study was then explained to eligible women with the aid of an information sheet and informed consent was obtained. Participants had examinations in the same order. TPU and EVU were performed first, with the patient in supine position and EAU was performed with the patient lying in the left lateral position. The St Marks Incontinence Scoring system ${ }^{28}$ scores the type and frequency of anal incontinence (gas, fluid, solid) and the impact on daily life, the need to wear a pad or plug, the use of constipating medication, and the presence of urgency. It gives a total score from 0 (complete continence) to 24 (complete incontinence). In the present study the score was modified by scoring the symptom of faecal urgency on a five-point frequency scale from 0 (never) to 4 (always), in contrast to the original scoring of 0 (absent) or 4 (present).

All ultrasound examinations were performed by an investigator experienced in imaging of the anal sphincter using the B and K Viking 2400 scanner (Gentofte, Denmark) fitted with a 3.5-6 MHz (type 8802) convex array transducer (focal point $40 \mathrm{~mm}$ and focal range $10-135 \mathrm{~mm}$ ), a 4-9 MHz (type 8806) endovaginal transducer (focal point $35 \mathrm{~mm}$ and focal range $4-65 \mathrm{~mm}$ ) and a $12-16 \mathrm{MHz}$ (type 2050) anorectal transducer (focal point up to $20 \mathrm{~mm}$ and focal range $5-45 \mathrm{~mm}$ ). Transperineal images were obtained with the patient in supine position. The convex array transducer was transversely positioned on the perineum between the anus and the introitus, and progressively inclined until the " $U$ "-shaped sling of the puborectalis muscle was visible. The entire anal canal could be scanned by changing the probe's inclination. Endovaginal ultrasonographic evaluation was also performed with the patient in supine position. The endovaginal transducer was placed vertically on the posterior fourchette in the transverse fashion, directed posteriorly towards the anal sphincter complex. Imaging of the complete anal sphincter complex occurred by changing the probe's inclination. EAU was performed with the patient in left lateral position. After insertion of the transducer up to the level of the anorectal junction, the crystal assembly was moved inside the transducer head by pressing the control buttons on the transducer handle. The transducer itself does not need to be moved after insertion. All three transducers were covered with lubricant gel and inserted into a transducer cover also covered with ultrasound gel.

For all three ultrasound methods two-dimensional (2D) images of the anal sphincter were collected at four levels. The first level was the level of the puborectalis portion of the levator ani muscle, which defines the level of the anorectal junction, and is visible as a "U"-shaped sling. The external sphincter was further subdivided into three levels: 
deep (proximal), superficial (mid), and subcutaneous (distal). The deep part can be seen coming forward from each side of the puborectalis as "wings" to join with the superficial part, which forms a complete ring around the anal canal. The subcutaneous level starts at the termination of the IAS. The normal IAS was seen as a continuous hypoechoic band inside the EAS. The normal striated muscle of the EAS was seen as a band of mixed echogenicity. EVU and TPU images of an intact deep, superficial, and subcutaneous level are shown in Figs 1 and 2. A defect was defined as any discontinuity in the normal appearance of the sonographic texture of the IAS or EAS (Figs 3 and 4). The images were orientated such that anterior was at the 12 o'clock position. For EAU, 3D images were also performed.

After examination, the digital 2D images were made anonymous and used for analysis. Two of the authors (A.M.R. and Z.A.) analysed the images independently and were blinded to each other's results. Images of the three ultrasound modes were analysed separately. The two outcomes were compared and any discrepancies were arbitrated by one of the senior authors (R.T. or A.H.S.). The following information was documented of each ultrasound modality at all four levels: (1) image obtainable, (2) quality of image permitting analysis, (3) presence of a sphincter defect, and (4) if a defect was present, the depth and size of the defect were recorded. All sphincter defects diagnosed by EAU were classified using the endoanal sonography scoring system described by Norderval et al., ${ }^{29}$ which has been shown to correlate with symptoms of anal incontinence. This scoring system is calculated by grading the depth, and maximum radial and longitudinal extension of both the IAS and EAS defects, in which a total score of 0 represents no defect and a score of 7 a maximal defect.

EVU and TPU were compared to the reference standard EAU. Sensitivity, specificity, positive and negative predictive values were calculated. The $95 \%$ confidence intervals were calculated according to the efficient-score method (corrected for continuity) as described by Newcombe. ${ }^{30}$ The main determinant of the sample size was the accuracy of the estimates of sensitivity and specificity. Based on the assumption of a 30\% prevalence of anal sphincter defects in the population of interest, a sample size of 150 women would provide 45 women with sphincter defects. Forty-five women with a sphincter defect would give a confidence interval of 65 to $90 \%$ assuming a true rate of sensitivity of $80 \%$. One hundred and five women with an intact sphincter would provide a confidence interval of 83 to $95 \%$ when assuming a specificity of $90 \%$. A sample size of at least 150 women is therefore likely to provide good accuracy of the sensitivity and specificity.

\section{Results}

Between January 2009 and May 2010165 women were recruited. For this analysis we excluded 4 women as they were seen in clinic over 12 months post-partum. Of the remaining 161 women the reasons for referral to the perineal clinic were: routine follow-up after OASIs in 98 (61\%),

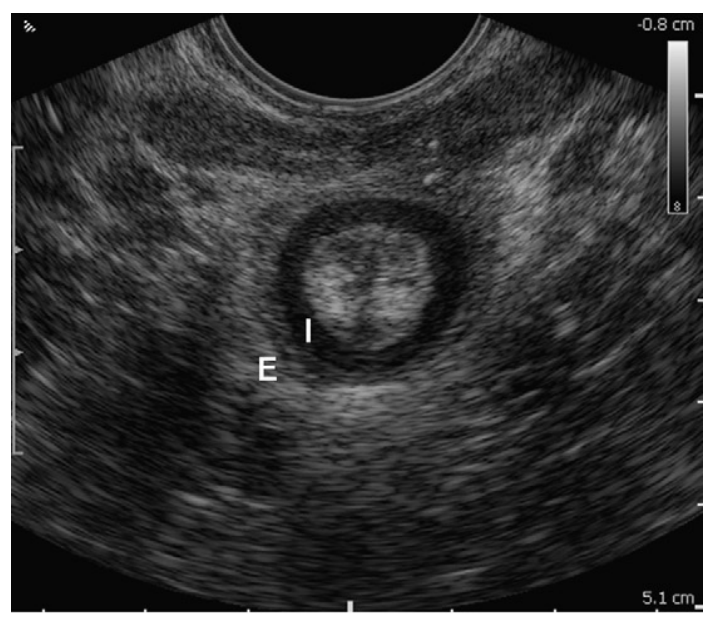

(a)

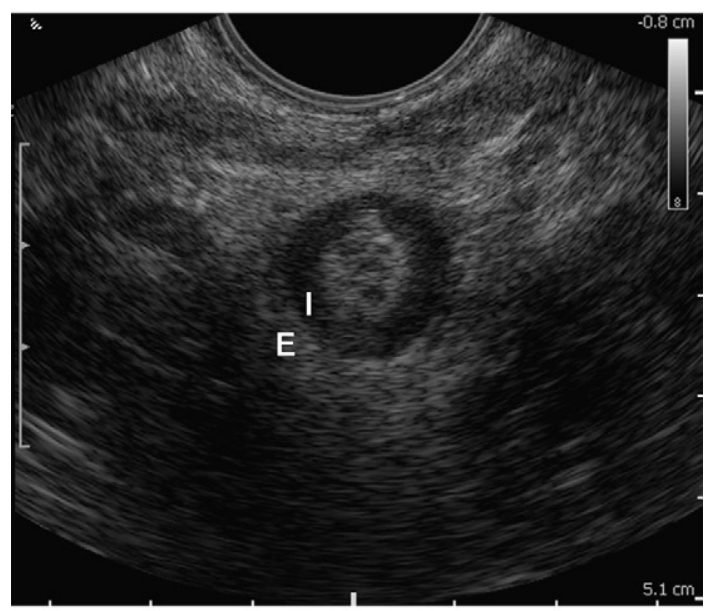

(b)

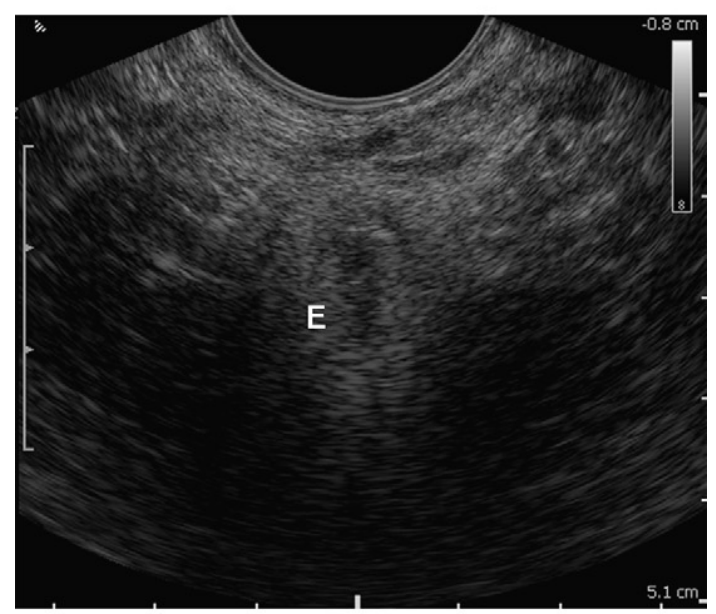

(c)

Figure 1 An intact sphincter shown at the deep (a), superficial (b), and subcutaneous (c) level using EVU. E, EAS; I, IAS.

subsequent pregnancy following OASIs in 52 (32\%; 46 antenatal, 6 postnatal), and postpartum bowel symptoms in 11 (7\%). The mean follow-up after OASIs was $13 \pm 11$ weeks. The women in subsequent pregnancies were seen 


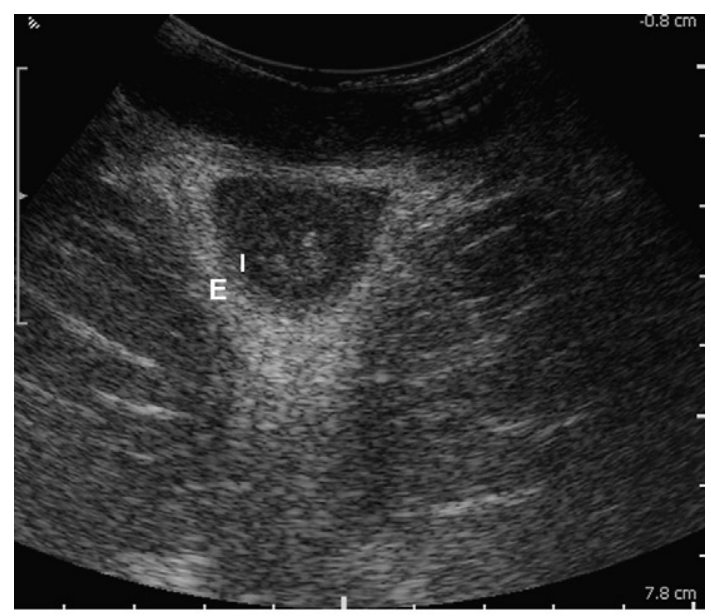

(a)

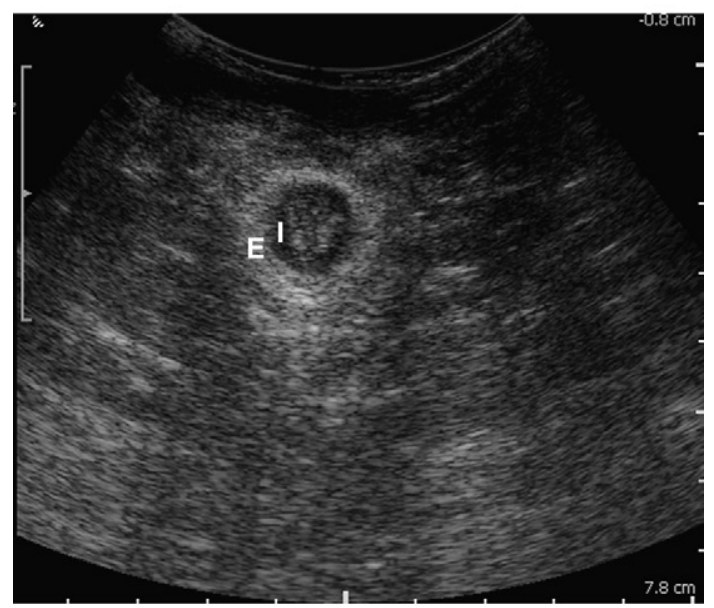

(b)

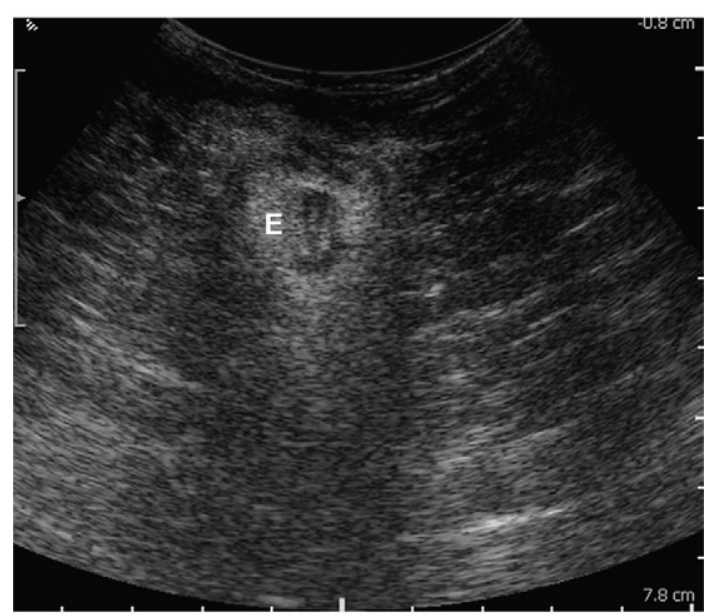

(c)

Figure 2 An intact sphincter shown at the deep (a), superficial (b), and subcutaneous (c) level using TPU. E, EAS; I, IAS.

antenatally between 26-38 weeks of gestation and postnatally at a mean of $11.7 \pm 2$ weeks (SD 2). The women suffering from bowel symptoms were seen at a mean of $33.5 \pm 22.1$ weeks post-partum. The mean age of

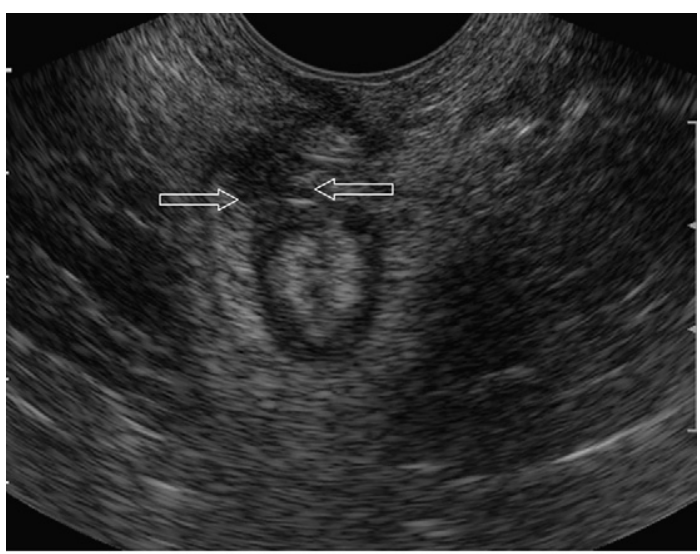

(a)

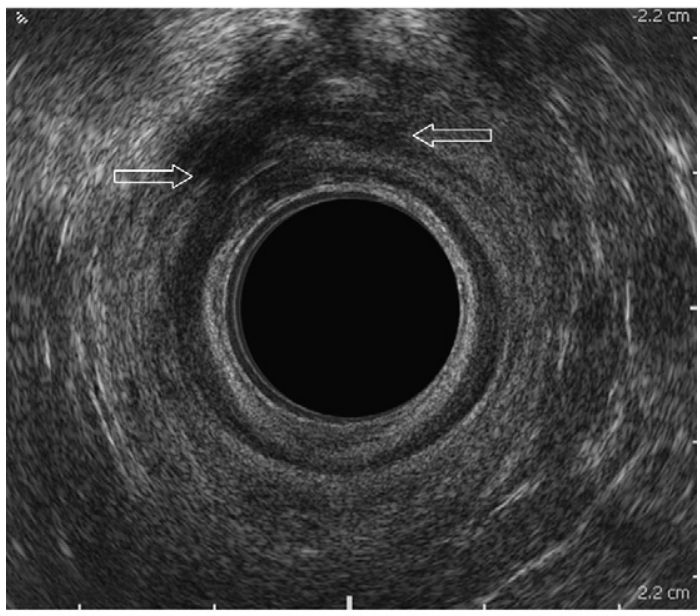

(b)

Figure 3 A defect in the EAS (between arrows) on EVU (a) and EAU (b) in an asymptomatic woman seen for follow-up after OASI.

participants was $31.5 \pm 5.4$ years (range $20-43$ ) and the main ethnic groups were Caucasian $[n=87(54 \%)]$ and Asian $[n=36(22 \%)]$. The median modified St Mark's Incontinence Score was 0 (range $0-20$ ), with 103 (64\%) women having a score of 0 and $132(82 \%)$ scoring $\leq 4$.

All three imaging procedures were well tolerated by all patients and no adverse events were reported. On EAU a defect was found in 42 (26\%) women: 19 (45\%) women had an isolated EAS defect; three (7\%) had an isolated IAS defect; and 20 (48\%) had a combined EAS and IAS defect. Twenty-five (60\%) of the defects were found in the group of women who came for routine follow-up after OASIs, 12 (29\%) in the group of women who were seen antenatally in their subsequent pregnancy following OASIs and five (12\%) in the women with postnatal bowel symptoms. No defects were found in the women seen postnatally in their subsequent pregnancy following OASIs. The median endoanal sonography score of the sphincter defects seen on EAU was 3 (range $2-7$ ). The score was 2 in seven (17\%), 3 in $15(36 \%)$, 4 in seven (17\%), 5 in five (12\%), 6 in five (12\%) and 7 in three (7\%) women. Table 1 lists the defect characteristics of the score for the women with defects visualized using EAU. 


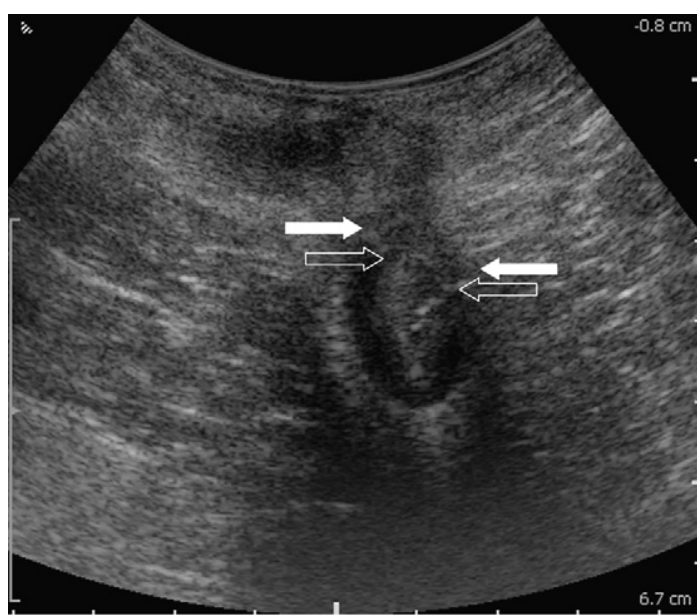

(a)

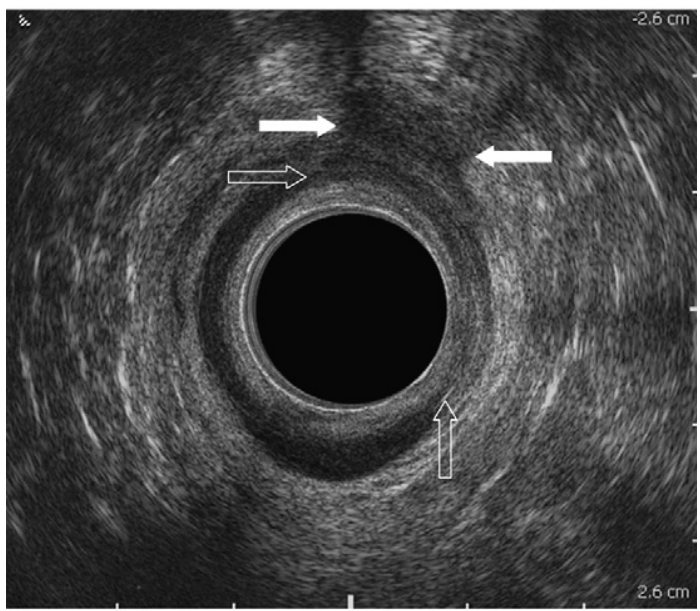

(b)

Figure 4 A defect in the EAS (white arrows) and IAS (open arrows) on TPU (a) and EAU (b) in a woman suffering from anal incontinence, seen for follow-up after OASI.

\section{EVU}

In one participant the endovaginal transducer was faulty at the time of examination. She had no defect on EAU. The results of the analysis of the EVU therefore refer to 160 women.
The availability and analysability of the endovaginal images are presented in Table 2. As the subcutaneous level was only analysable in $61 \%$ of women, the presence of defects was analysed based on at least one available and analysable level of the EAS combined with an analysable IAS. This was the case in 140 (87\%) women.

EVU revealed anal sphincter defects in $31(19 \%)$ women; 14 (45\%) had an EAS defect and 22 (71\%) an IAS defect. More specifically 9 (29\%) had an isolated EAS defect, 17 (55\%) had an isolated IAS defect, and five (16\%) had a combined defect of the EAS an IAS. The comparison of EVU with EAU is presented in Table 3.

\section{TPU}

TPU was performed in all participants. The obtainable images and analysability of the different levels of TPU are listed in Table 4. The difficulty in analysing the more distal levels of the anal sphincter is apparent. Therefore the presence of defects based on at least one obtainable and analysable level of the EAS combined with an analysable IAS was analysed as was done for EVU. In 131 (81\%) women both the IAS and one level of the EAS were analysable.

On TPU 33 (20\%) women were found to have an anal sphincter defect; 27 (82\%) had an EAS defect and 19 (58\%) an IAS defect. More specifically $14(42 \%)$ had isolated EAS defects, six (18\%) had isolated IAS defects, and 13 (39\%) combined defects. The results of the comparison of TPU and EAU are listed in Table 5.

As can be seen in Tables 3 and 5, a non-analysable result appears to be related to having a sphincter defect. Therefore the predictive value (95\% confidence interval) was calculated for a sphincter defect of a non-analysable result. For EVU this was 55\% (32-76\%) for any sphincter defect, $45 \%$ (24-68\%) for an EAS defect, and 25\% (10-49\%) for an IAS defect. For TPU the positive predictive value for a nonanalysable result was $47 \%$ (29-65\%) for any defect or an EAS defect, and $23 \%(11-43 \%)$ for an IAS defect.

\section{Discussion}

EAU using a rotating probe is the validated reference standard in the identification of anal sphincter defects. ${ }^{2,3}$ However, unlike EVU and TPU, the probe is not universally available in obstetrics and gynaecology units. The use of

Table 1

Endoanal sonography scoring system for defects seen on endoanal ultrasound $(n=42)$.

\begin{tabular}{|c|c|c|c|c|}
\hline & Score 0 & Score 1 & Score 2 & Score 3 \\
\hline \multicolumn{5}{|c|}{ External anal sphincter } \\
\hline Length of defect & $3(\leq 50 \%)$ & $39(>50 \%)$ & - & - \\
\hline Depth of defect & 3 (no defect) & 8 (partial $(\geq 50 \%))$ & $\begin{array}{l}27 \text { (total and } \leq 90^{\circ} \\
\text { radial extension) }\end{array}$ & $\begin{array}{l}4 \text { (total and }>90^{\circ} \\
\text { radial extension) }\end{array}$ \\
\hline \multicolumn{5}{|c|}{ Internal anal sphincter } \\
\hline Length of defect & $23(\leq 50 \%)$ & $19(>50 \%)$ & - & - \\
\hline Depth of defect & 19 (no defect) & $\begin{array}{l}13 \text { (total and } \leq 90^{\circ} \\
\text { radial extension) }\end{array}$ & $\begin{array}{l}10 \text { (total and }>90^{\circ} \\
\text { radial extension) }\end{array}$ & - \\
\hline
\end{tabular}


Table 2

The ability to obtain and analyse external anal sphincter images as per level on endovaginal ultrasound ( $n=160$ ).

\begin{tabular}{|c|c|c|c|c|}
\hline & & Deep level & Superficial level & Subcutaneous level \\
\hline Image obtainable & & $153(96 \%)$ & $143(89 \%)$ & $142(89 \%)$ \\
\hline \multirow[t]{3}{*}{ Reason image not obtainable } & Unable to visualize & $2(1 \%)$ & $2(1 \%)$ & $3(2 \%)$ \\
\hline & Image taken at wrong level & $5(3 \%)$ & $12(7 \%)$ & $9(6 \%)$ \\
\hline & Unknown & - & $3(2 \%)$ & $6(4 \%)$ \\
\hline Image analysable & & $145(91 \%)$ & $130(81 \%)$ & $98(61 \%)$ \\
\hline
\end{tabular}

more readily available, conventional probes to evaluate the anal sphincter could therefore facilitate assessment of the anal sphincter following childbirth, during subsequent pregnancies following OASIs and in women presenting with faecal incontinence. Such assessment has been shown to make a positive contribution to the management and was useful in counselling women regarding the mode of delivery in subsequent pregnancies following OASIs. ${ }^{24}$

Although EVU and TPU to visualize the normal anal sphincter anatomy as well as its disruptions have been described in many studies, validation against a reference standard has not been consistently reported. Some studies did not confirm any of their findings, $6,14,15$ while others were able to confirm TPU ${ }^{16}$ and EVU ${ }^{11,13}$ findings in symptomatic women opting for sphincter reconstructive surgery. The limitation of the latter was that although only some positive findings were confirmed none of the negative findings were checked. Previous comparative studies with EAU and TPU showed sensitivities of $50 \%$ in women with urinary incontinence ${ }^{17}$ and $83 \%$ in a group of post-partum primiparous patients. ${ }^{18}$ However, both EAU and TPU were evaluated at the same time and evaluation of the images obtained using TPU could therefore have been biased by the analysis of EAU images. Results of the comparison of EVU with EAU vary considerably ${ }^{5,8-10}$ and again results should be interpreted with caution as sample size was small and the investigator was not blinded to the EAU results when evaluating the EVU images. Frudinger et al. ${ }^{7}$ compared the results of EVU and EAU in a small sample of 48 women where the endovaginal examinations were reviewed by an observer unaware of the anal endosonographic findings. They showed that the sensitivity of EVU for the detection of anal sphincter defects is low (44\% for IAS and 48\% for EAS defects), but specificity is high (96\% for IAS and $88 \%$ for EAS defects). However, they used a $10 \mathrm{MHz}$ rectal endoprobe and a $10 \mathrm{MHz}$ modified vaginal probe for EVU and no studies have been published comparing the findings of EVU using a standard endovaginal probe to that of a reference standard.

To date the present study is the largest study with adequate power comparing TPU and EVU to EAU for detecting anal sphincter defects. Images of the three ultrasound methods were analysed separately ensuring EAU results could not have influenced the evaluation of the images obtained using TPU and EVU. It was found that for the detection of any defect the positive predictive value was 48\% for EVU and 54\% for TPU, but the negative predictive value were $85 \%$ and $90 \%$ respectively. Hence TPU and EVU are good in detecting normality, as shown by the high specificity, but the sensitivity for detecting anal sphincter defects is much lower, especially for EVU

Visualization and interpretation of the anal sphincter images was found to be difficult with both TPU and EVU, especially at the more distal levels. Therefore, the presence of defects in the anal sphincter were compared when at least one level of the EAS as well as the IAS were adequately

Table 3

Comparison of findings on endovaginal ultrasound and endoanal ultrasound $(n=160)$.

\begin{tabular}{|c|c|c|c|c|c|}
\hline & & \multicolumn{3}{|c|}{ Endovaginal ultrasound } & \\
\hline & & Defect & Intact & Non-analysable & \\
\hline \multicolumn{6}{|c|}{ Endoanal ultrasound } \\
\hline \multirow[t]{4}{*}{ Any defect } & Defect $(n=42)$ & 15 & 16 & $11(26 \%)^{a}$ & Sensitivity $=48 \%(30-67 \%)^{b}$ \\
\hline & Intact $(n=118)$ & 16 & 93 & $9(8 \%)^{c}$ & Specificity $=85 \%(77-91 \%)^{b}$ \\
\hline & & & & & $\mathrm{PPV}=48 \%(30-67 \%)$ \\
\hline & & & & & $\mathrm{NPV}=85 \%(77-91 \%)$ \\
\hline \multirow[t]{4}{*}{ EAS defects } & Defect $(n=39)$ & 9 & 21 & $9(23 \%)^{a}$ & Sensitivity $=30 \%(15-49 \%)^{b}$ \\
\hline & Intact $(n=121)$ & 5 & 105 & $11(9 \%)^{c}$ & Specificity $=95 \%(89-98 \%)^{b}$ \\
\hline & & & & & $P P V=64 \%(36-86 \%)$ \\
\hline & & & & & $\mathrm{NPV}=83 \%(75-89 \%)$ \\
\hline \multirow[t]{4}{*}{ IAS defects } & Defect $(n=23)$ & 9 & 9 & $5(22 \%)^{a}$ & Sensitivity $=50 \%(27-73 \%)^{b}$ \\
\hline & Intact $(n=137)$ & 13 & 109 & $15(11 \%)^{c}$ & Specificity $=89 \%(82-94 \%)^{\mathrm{b}}$ \\
\hline & & & & & $\mathrm{PPV}=41 \%(21-63 \%)$ \\
\hline & & & & & $\mathrm{NPV}=92 \%(86-96 \%)$ \\
\hline
\end{tabular}

PPV, positive predictive value; NPV, negative predictive value.

a Percentage non-analysable images within defects on endoanal ultrasound.

b Sensitivity and specificity of analysable images.

c Percentage non-analysable images within intact anal sphincter on endoanal ultrasound. 
Table 4

The ability to obtain and analyse external anal sphincter images as per level on transperineal ultrasound ( $n=161)$.

\begin{tabular}{|c|c|c|c|c|}
\hline & & Deep level & Superficial level & Subcutaneous level \\
\hline Image obtainable & & $156(97 \%)$ & $153(95 \%)$ & $143(89 \%)$ \\
\hline \multirow[t]{3}{*}{ Reason image not obtainable } & Unable to visualize & $2(1 \%)$ & $2(1 \%)$ & $3(2 \%)$ \\
\hline & Image taken at wrong level & $3(2 \%)$ & $3(2 \%)$ & $6(4 \%)$ \\
\hline & Unknown & - & $3(2 \%)$ & $9(6 \%)$ \\
\hline Image analysable & & $135(84 \%)$ & $131(81 \%)$ & $87(54 \%)$ \\
\hline
\end{tabular}

visualized. Adequate images were not obtainable in $19 \%$ and $13 \%$ of women using TPU and EVU, respectively. Although a non-analysable result could imply missing a potential defect, it is not wrongly classifying a sphincter defect as an intact sphincter and therefore it was analysed separately. Having a non-analysable result appeared to be related to the presence of a sphincter defect (Tables 3 and 5) and the predictive value for a sphincter defect was comparable for positive and non-analysable TPU and EVU findings.

The most probable reason for difficulty in analysing the distal levels of the anal sphincter complex is related to the exaggerated angle of inclination of the external probe with consequent loss of acoustic contact. This could have resulted in application of greater pressure, leading to deformity particularly of the IAS and leading to artefacts. Furthermore, it is sometimes difficult to image the posterior and lateral parts of the EAS, although this is of relatively minor importance as the focus in this group of patients is on the anterior part of the anal sphincter. Difficulty in analysing images of EVU was previously reported in $23-24 \%$, in studies using the rotating endoprobe. ${ }^{8,9}$ This was attributed partially to a learning curve, ${ }^{8}$ but also lack of acoustic contact within the vagina ${ }^{9}$ and limitation in viewing the dorsolateral part of the EAS caused by the focal range of the transducer. ${ }^{8}$ A further study by Frudinger et al. ${ }^{7}$ using a rotating endoprobe found only $6 \%$ of endovaginal images was not analysable. However, they stated that the normal anatomy limits EVU to imaging only the proximal level of the anal canal. The anal canal cannot be scanned in a plane parallel to its axis using EVU as the vaginal axis is divergent from that of the anal canal. Using the standard endovaginal probe Sandridge et al. ${ }^{6}$ found five out of 70 examinations were unsatisfactory for assessment of the EAS. However, these previous studies did not describe and analyse all three levels of the EAS as done in the present study. In fact studies using EVU and TPU are variable in terms of reporting levels. Most studies do not describe any anal sphincter levels $s^{5,8-10,14,17,25}$ or when they do report on imaging different transverse planes, they do not include the subcutaneous level. ${ }^{6,12,13,15}$ Peschers et al. ${ }^{16}$ report visualizing the anal canal from the puborectalis to the subcutaneous EAS, but provided no data on images at each level. Only one previous study using TPU has described visualization of the three levels of the EAS including the subcutaneous level ${ }^{18}$ and was able to obtain images of all three levels for all 20 nulliparous as well as all 20 primiparous participants.

The generalizability of the results of the present study is limited because the findings are dependent on the type of equipment used, the training of the operators, and the population studied. Positive and negative predictive values are dependent on the prevalence of the disease and can therefore only be generalized to populations with the same prevalence of anal sphincter defects. The present study population consisted of mostly asymptomatic, young women, and predictive values might be different in an older, more symptomatic population. The sensitivity could

Table 5

Comparison of findings of transperineal ultrasound and endoanal ultrasound $(n=161)$.

\begin{tabular}{|c|c|c|c|c|c|}
\hline & & \multicolumn{3}{|c|}{ Transperineal ultrasound } & \\
\hline & & Defect & Intact & Non-analysable & \\
\hline \multicolumn{6}{|c|}{ Endoanal ultrasound } \\
\hline \multirow[t]{2}{*}{ Any defect } & Defect $(n=42)$ & 18 & 10 & $14(33 \%)^{\mathrm{a}}$ & Sensitivity $=64 \%(44-81 \%)^{\mathrm{b}}$ \\
\hline & Intact $(n=119)$ & 15 & 88 & $16(13 \%)^{c}$ & $\begin{array}{l}\text { Specificity }=85 \%(77-91 \%)^{b} \\
P P V=54 \%(37-71 \%) \\
N P V=90 \%(82-95 \%)\end{array}$ \\
\hline \multirow[t]{2}{*}{ EAS defects } & Defect $(n=39)$ & 15 & 10 & $14(36 \%)^{a}$ & Sensitivity $=60 \%(39-78 \%)^{b}$ \\
\hline & Intact $(n=122)$ & 12 & 94 & $16(13 \%)^{c}$ & $\begin{array}{l}\text { Specificity }=89 \%(81-94 \%)^{b} \\
P P V=55 \%(36-74 \%) \\
N P V=90 \%(83-95 \%)\end{array}$ \\
\hline \multirow[t]{2}{*}{ IAS defects } & Defect $(n=23)$ & 8 & 8 & $7(30 \%)^{a}$ & Sensitivity $=50 \%(25-74 \%)^{b}$ \\
\hline & Intact $(n=138)$ & 11 & 104 & $23(17 \%)^{c}$ & $\begin{array}{l}\text { Specificity }=90 \%(83-95 \%)^{\mathrm{b}} \\
\mathrm{PPV}=42 \%(21-66 \%) \\
\mathrm{NPV}=93 \%(86-97 \%)\end{array}$ \\
\hline
\end{tabular}

PPV, positive predictive value; NPV, negative predictive value.

a Percentage non-analysable images within defects on endoanal ultrasound.

b Sensitivity and specificity of analysable images.

c Percentage non-analysable images within intact anal sphincter on endoanal ultrasound. 
also have been affected by the size and depth of the defects studied. Most defects were of $\leq 90^{\circ}$ radial extension. It is possible that unlike with EAU, smaller defects may not be apparent with TPU and EVU because the anal sphincter is in a relaxed state without anal distension.

To ensure quick patient turnover, in our busy perineal clinic, the same physician performed all ultrasound examinations for the same patient. To reduce bias caused by information gathered during history taking, and performing EAU, the images were evaluated at a different time.

Examination of post-partum and antenatal women following OASIs and/or those presenting with post-partum anal incontinence using a standard and readily available perineal or vaginal probe can be used as a screening method. If TPU or EVU reveals an intact anal sphincter no further tests are necessary. If a defect is seen or if the image taken is not analysable, further investigation with EAU is recommended. However, one should be aware that when using these methods not all anal sphincter defects will be identified. The recent use of 3D TPU in post-partum women is promising, ${ }^{31}$ but needs to be compared to EAU.

In conclusion, EAU using a rotating endoprobe is the validated reference standard in the identification of anal sphincter defects. However, this technique is not available universally and anal sphincter imaging has also been performed using conventional probes. The present comparative study has shown that if EAU is unavailable TPU and/or EVU can be useful in identifying normality, but it is not always possible to identify an underlying sphincter defect.

\section{Acknowledgements}

The authors thank B and K Medical (Denmark) for the loan of the scanner. A.-M.R. was funded by the Mayday Childbirth Charity Fund. Z.A. was provided with a research grant by the International Urogynecological Association in 2009.

\section{References}

1. Law PJ, Bartram CI. Anal endosonography: technique and normal anatomy. Gastrointest Radiol 1989;14:349.

2. Sultan AH, Kamm MA, Talbot IC, et al. Anal endosonography for identifying external sphincter defects confirmed histologically. Br J Surg 1994;81:463.

3. Deen KI, Kumar D, Williams JG, et al. Anal sphincter defects: correlation between endoanal ultrasound and surgery. Ann Surg 1993;218:201.

4. Gold DM, Bartram CI, Halligan S, et al. Three-dimensional endoanal sonography in assessing anal canal injury. Br J Surg 1999;86:365.

5. Sultan AH, Loder PB, Bartram CI, et al. Vaginal endosonography: new approach to image the undisturbed anal sphincter. Dis Colon Rectum 1994;37:1296.

6. Sandridge DA, Thorp Jr JM. Vaginal endosonography in the assessment of the anorectum. Obstet Gynecol 1995;86:1007.

7. Frudinger A, Bartram CI, Kamm MA. Transvaginal versus anal endosonography for detecting damage to the anal sphincter. AJR Am J Roentgenol 1997;168:1435.

8. Poen AC, Felt-Bersma RJF, Cuesta MA, et al. Vaginal endosonography of the anal sphincter complex is important in the assessment of faecal incontinence and perianal sepsis. Br J Surg 1998;85:359.
9. Ramírez JM, Aguilella V, Martínez M, et al. The utility of endovaginal sonography in the evaluation of fecal incontinence. Rev Esp Enferm Dig 2005;97:317.

10. Stewart LK, Wilson SR. Transvaginal sonography of the anal sphincter: reliable, or not? AJR Am J Roentgenol 1999;173:179.

11. Alexander AA, Liu J-B, Merton DA, et al. Fecal incontinence: transvaginal US evaluation of anatomic causes. Radiology 1996;199:529.

12. Kammerer-Doak DN, Wesol AB, Rogers RG, et al. A prospective cohort study of women after primary repair of obstetric anal sphincter laceration. AJOG 1999;181:1317.

13. Timor-Tritsch IE, Monteagudo A, Smilen SW, et al. Simple ultrasound evaluation of the anal sphincter in female patients using a transvaginal transducer. Ultrasound Obstet Gynecol 2005;25:177.

14. Timor-Tritsch IE, Monteagudo A, Porges RF, et al. The use of a $15-7-\mathrm{MHz}$ "small-parts" linear transducer to evaluate the anal sphincter in female patients. Ultrasound Obstet Gynecol 2005;25:206.

15. Hall RJ, Rogers RG, Saiz L, et al. Translabial ultrasound assessment of the anal sphincter complex: normal measurements of the internal and external anal sphincters at the proximal, mid-, and distal levels. Int Urogynecol J 2007;18:881.

16. Peschers UM, DeLancey JOL, Schaer GN, et al. Exoanal ultrasound of the anal sphincter: normal anatomy and sphincter defects. BJOG 1997; 104:999.

17. Lohse $\mathrm{C}$, Bretones $\mathrm{S}$, Boulvain $\mathrm{M}$, et al. Trans-perineal versus endo-anal ultrasound in the detection of anal sphincter tears. Eur J Obstet Gynecol Reprod Biol 2002;103:79.

18. Roche B, Deléaval J, Fransioli A, et al. Comparison of transanal and external perineal ultrasonography. Eur Radiol 2001;11:1165.

19. Kleinübing Jr H, Jannini JF, Malafaia O, et al. Transperineal ultrasonography: new method to image the anorectal region. Dis Colon Rectum 2000;43:1572.

20. Roos AM, Thakar R, Sultan AH. Outcome of primary repair of obstetric anal sphincter injuries (OASIS) - does the grade of tear matter? Ultrasound Obstet Gynecol 2010;36:368.

21. Mahony R, Behan M, Daly L, et al. Internal anal sphincter defect influences continence outcome following obstetric anal sphincter injury. Am J Obstet Gynecol 2007;196:217.e1.

22. Nichols CM, Lamb EH, Ramakrishnan V. Differences in outcomes after third- versus fourth-degree perineal laceration repair: a prospective study. Am J Obstet Gynecol 2005;193:530.

23. Norderval S, Öian P, Revhaug A, et al. Anal incontinence after obstetric sphincter tears: outcome of anatomic primary repairs. Dis Colon Rectum 2005;48:1055.

24. Scheer I, Thakar R, Sultan AH. Mode of delivery after previous obstetric anal sphincter injuries (OASIS) - a reappraisal? Int Urogynecol J 2009; 20:1095.

25. Maslovitz S, Jaffa A, Levin I, et al. The clinical significance of postpartum transperineal ultrasound of the anal sphincter. Eur J Obstet Gynecol Reprod Biol 2007;134:115.

26. Örnö A-K, Maršál K, Herbst A. Ultrasonographic anatomy of perineal structures during pregnancy and immediately following obstetric injury. Ultrasound Obstet Gynecol 2008;32:527.

27. Thakar R, Sultan AH. Postpartum problems and the role of a perineal clinic. In: Sultan AH, Thakar R, Fenner DE, editors. Perineal and anal sphincter trauma. $1^{\text {st }}$ ed. London: Springer-Verlag; 2007. p. 65-79.

28. Vaizey CJ, Carapeti E, Cahill JA, et al. Prospective comparison of faecal incontinence grading systems. Gut 1999;44:77.

29. Norderval S, Markskog A, Røssaak K, et al. Correlation between anal sphincter defects and anal incontinence following obstetric sphincter tears: assessment using scoring systems for sonographic classification of defects. Ultrasound Obstet Gynecol 2008;31:78.

30. Newcombe RG. Two-sided confidence intervals for the single proportion: comparison of seven methods. Stat Med 1998;17:857.

31. Valsky DV, Messing B, Petkova R, et al. Postpartum evaluation of the anal sphincter by transperineal three-dimensional ultrasound in primiparous women after vaginal delivery and following surgical repair of thirddegree tears by the overlapping technique. Ultrasound Obstet Gynecol 2007;29:195. 